\title{
Influência do glifosato na eficiência nutricional do nitrogênio, manganês, ferro, cobre e zinco em soja resistente ao glifosato
}

\author{
Glyphosate influence on nitrogen, manganese, iron, copper and zinc nutritional efficiency in \\ glyphosate resistant soybean
}

\author{
Ademar Pereira Serra ${ }^{\mathrm{I}}$ Marlene Estevão MarchettiI ${ }^{\mathrm{II}}$ Ana Carina da Silva Candido ${ }^{\mathrm{II}}$ \\ Ana Caroline Ribeiro Dias ${ }^{\text {III }}$ Pedro Jacob Christoffoleti ${ }^{\text {III }}$
}

\section{RESUMO}

Com o desenvolvimento da soja resistente ao glifosato, Roundup Ready (RR), observa-se um aumento considerável no uso desse herbicida, com aplicações de três a quatro vezes durante o ciclo da cultura. Dessa forma, essas aplicações podem estar influenciando a nutrição mineral da cultura. Objetivou-se realizar este experimento para avaliar a influência do glifosato na eficiência nutricional de $\mathrm{N}, \mathrm{Mn}, \mathrm{Cu}$, $\mathrm{Zn}$ e Fe pela soja transgênica cv. 'P98R31 RR'. O experimento foi realizado em casa de vegetação, na ESALQ/USP, Piracicaba (SP), em 2009. A unidade experimental foi constituida por vaso contendo $11 \mathrm{~kg}$ de substrato (NITOSSOLO VERMELHO Eutroférrico latossólico), com duas plantas por vaso. Os tratamentos foram arranjados em um esquema fatorial $5 X 5$, com cinco níveis do fator Mn (0, 20, 40, 60 e $\left.80 \mathrm{mg} \mathrm{dm}^{-3}\right)$ e cinco de glifosato $\left(0 ; 0,648 ; 1,296 ; 1,944\right.$ e 2,592kg i.a. ha $\left.\mathrm{h}^{-1}\right)$, sendo que o Mn foi fornecido a partir do sulfato de manganês ( $\left.\mathrm{MnSO}_{4} \cdot \mathrm{H}_{2} \mathrm{O}\right)$. O delineamento experimental foi em blocos casualizados, com quatro repetições. Não houve influência na resposta das plantas com relação ao fator $M$ n. A aplicação de glifosato interferiu de forma negativa na eficiência nutricional da planta e nos teores totais de $\mathrm{N}, \mathrm{Mn}, \mathrm{Cu}, \mathrm{Zn}$ e Fe. A utilização de glifosato causou redução ao número de nódulos e redução na produção de massa seca.

Palavras-chave: nutrição mineral, soja, herbicida.

\section{ABSTRACT}

After development of glyphosate-resistant (GR) soybean, there is a considerable raise in the use of this herbicide, with three to four applications during the culture cycle. Thus, these applications may be influencing the mineral nutrition of the crop. So, the aim of this research was evaluate the glyphosate influence on uptake, translocation and use efficiency of $N, M n$, $\mathrm{Cu}, \mathrm{Zn}$ and $\mathrm{Fe}$ by (GR) soybean 'P98R31' cultivar. The experiment was conducted in the greenhouse at ESALQ/USP, Piracicaba, State of São Paulo, Brazil, in 2009. The experimental unit was formed by $11 \mathrm{~kg}$ vase $e^{-1}$ of soil (Rhodic Paleudult) with two plants in each vase. The treatments have been arranged in a factorial pathway $5 X 5$, with five levels of the factor $\mathrm{Mn}\left(0,20,40,60\right.$ and $\left.80 \mathrm{mg} \mathrm{dm}^{-3}\right)$ and five of glyphosate drifts $\left(0 ; 0,648 ; 1,296 ; 1,944\right.$ e 2,592kg e.a. ha $\left.a^{-1}\right)$ and the Mn was supplied by the manganese sulfate $\left(\mathrm{MnSO}_{4} \mathrm{H}_{2} \mathrm{O}\right)$. The experimental design was randomized blocks, with four repetitions. There was no influence on response from plants concerning the levels of Mn used into the experiment. The application of glyphosate interfered on mineral nutrition of soybean and the total contents of $\mathrm{N}, \mathrm{Mn}, \mathrm{Cu}, \mathrm{Zn}$ and $\mathrm{Fe}$. The use of glyphosate has caused reduction of the nodules number and reduced the output of dry mass.

Key words: mineral nutrition, soybean, herbicide.

\section{INTRODUÇÃO}

Com o desenvolvimento da soja [Glycine $\max (\mathrm{L}$.) Merr.] geneticamente modificada, resistente ao glifosato [N-(phosphonomethyl)glycine], tem-se observado aumento considerável na utilização desse herbicida aplicado, principalmente em pós-emergência, aplicando-se de três a quatro vezes durante o ciclo da soja. Essas sucessivas aplicações de um único produto

'Programa de Pós-graduação em Produção Vegetal, Universidade Federal da Grande Dourados (UFGD). Escola Superior de Agricultura Luiz de Queiroz (ESALQ), Universidade de São Paulo (USP), 79800-000, Dourados, MS, Brasil. E-mail: ademar.serra@hotmail.com. Autor para correspondência.

"Programa de Pós-graduação em Produção Vegetal, UFGD, Dourados, MS, Brasil.

IIIPrograma de Pós-graduação em Fitotecnia, ESALQ, USP, Piracicaba, SP, Brasil. 
interferem negativamente na nutrição da planta. Em estudos anteriores observou-se que o uso do herbicida glifosato em pós-emergência afeta o teor de micronutrientes nas plantas de soja Roundup Ready (RR) (EKER et al., 2006; NEUMANN et al., 2006). Resultado semelhante foi observado por CAKMAK et al. (2009) em soja convencional, observando que o glifosato interfere na absorção e translocação de Ca, $\mathrm{Mg}, \mathrm{Fe}$ e Mn. A frequência de aplicações de glifosato pode levar à indução de deficiências de ferro $(\mathrm{Fe})$, zinco (Zn) e manganês (Mn). SANTOS et al. (2007) observaram que N, Ca, Fe e Cu tiveram redução em seu teor na planta de soja RR, quando as mesmas foram tratadas com glifosato, sendo essas amostragens foliares realizadas no período de florescimento. No entanto, nem todos os nutrientes tiveram essa resposta, sendo que o Mg apresentou elevação em seu teor foliar mediante a aplicação de glifosato.

A resistência ao herbicida pela soja transgênica foi obtida pela inserção de um gene (AroA) oriundo do genoma da Agrobacterium sp., estirpe CP4, a qual codifica uma variante da enzima 5 enolpiruvilchiquimato-3-fosfato sintase (EPSPS), sendo a CP4 EPSPS especialmente resistente à inibição pelo glifosato (PADGETTE et al., 1995). Sob tratamento com esse herbicida, as plantas de soja não são afetadas, em virtude da ação continuada e sistemática dessa enzima alternativa, insensível ao produto. No entanto, o glifosato é prejudicial à fixação biológica do N, pois o Bradyrhizobium sp. tem a EPSPS suscetível ao glifosato (ZABLOTOWICZ \& REDDY, 2007). Além desse fato, ZOBIOLE et al. (2010a) relatam que o glifosato pode afetar a fixação biológica do $\mathrm{N}$, devido à redução do teor de níquel, sendo esse micronutriente essencial para os microrganismos simbióticos.

Dessa forma, a realização deste experimento teve como objetivo avaliar a influência do glifosato na eficiência nutricional de $\mathrm{N}, \mathrm{Mn}, \mathrm{Cu}, \mathrm{Zn}$ e Fe pela soja transgênica cv. 'P98R31', resistente ao glifosato em condições de casa de vegetação.

\section{MATERIAL E MÉTODOS}

O experimento foi desenvolvido em condições de casa de vegetação, no Departamento de Produção Vegetal da Escola Superior de Agricultura “Luiz de Queiroz" (ESALQ), na Universidade de São Paulo (USP), em Piracicaba (SP), em 2009, localizada entre as coordenadas geográficas de $22^{\circ} 42^{\prime} 30^{\prime \prime}$ de latitude Sul e $47^{\circ} 38^{\prime} 00^{\prime}$ de longitude Oeste, encontrando-se a uma altitude de $456 \mathrm{~m}$. Foi utilizado, como substrato, material de um NITOSSOLO VERMELHO Eutroférrico latossólico (EMBRAPA,
2006), coletado na camada de 20-40cm, na área experimental da fazenda "Areão", sendo realizadas quatro amostragens com peso aproximado em 500g cada, que foram secadas ao ar ambiente, destorroadas e passadas em peneira com malha de $4 \mathrm{~mm}$, para a determinação das características químicas e físicas: $\mathrm{pH}_{\mathrm{CaCl} 2}=4,8 ; \mathrm{MO}=6,5 \mathrm{~g} \mathrm{dm}^{-3} ; \mathrm{P}=3 \mathrm{mg} \mathrm{dm}^{-3} ; \mathrm{S}=16 \mathrm{mg} \mathrm{dm}^{-3}$; $\mathrm{K}=0,3 \mathrm{mmolc} \mathrm{dm}^{-3} ; \mathrm{Ca}=17,5 \mathrm{mmolc} \mathrm{dm}^{-3} ; \mathrm{Mg}=6 \mathrm{mmolc} \mathrm{dm}^{-3}$; $\mathrm{H}+\mathrm{Al}=20 \mathrm{mmolc} \mathrm{dm}^{-3} ; \mathrm{Al}=4,8 \mathrm{mmolc} \mathrm{dm}^{-3} ; \mathrm{SB}=23,5 \mathrm{mmol}_{\mathrm{c}}$ $\mathrm{dm}^{-3} ; \mathrm{T}=43,5 \mathrm{mmol}_{\mathrm{c}} \mathrm{dm}^{-3} ; \mathrm{V}(\%)=54 \mathrm{e} \mathrm{m}(\%)=2 ; \mathrm{Cu}=1,4 \mathrm{mg}$ $\mathrm{dm}^{-3} ; \mathrm{Fe}=52 \mathrm{mg} \mathrm{dm}^{-3} ; \mathrm{Zn}=0,55 \mathrm{mg} \mathrm{dm}^{-3} ; \mathrm{Mn}=46,4 \mathrm{mg} \mathrm{dm}^{-3}$; $\mathrm{B}=0,24 \mathrm{mg} \mathrm{dm}^{-3}$; Argila $=217,5 \mathrm{~g} \mathrm{~kg}^{-1}$; Silte $=108 \mathrm{~g} \mathrm{~kg}^{-1}$; Areia $=674,5 \mathrm{~g} \mathrm{~kg}^{-1}$; textura média.

Com base nos resultados da análise química do solo, foi realizada a calagem para a correção da acidez do solo, utilizando-se o calcário dolomítico finamente moído (PRNT=100\%), cuja composição apresentou $34,5 \%$ de óxido de cálcio $(\mathrm{CaO})$ e $18 \%$ de óxido de magnésio (MgO). Calculou-se então a quantidade necessária para elevar a saturação por bases a $65 \%$, sendo aplicados $245 \mathrm{mg} \mathrm{dm}^{-3}$. Os vasos foram mantidos úmidos com água destilada para manter a umidade equivalente a $60 \%$ do volume total de poros. $\mathrm{O}$ volume de água a aplicar foi estimado com base na densidade aparente (Dap) e no volume de poros (Vp) (EMBRAPA, 1997), permanecendo os vasos incubados por 30 dias. Após esse período, efetuou-se a adubação, sendo em seguida realizada a semeadura. As sementes foram tratadas com fungicida $\left(\right.$ Thiram $^{\circledR}$ ) na dose proporcional a $100 \mathrm{~g}$ i.a por $100 \mathrm{~kg}$ de semente. Anteriormente à semeadura, foi realizada a adução de potássio $\left(\mathrm{K}_{2} \mathrm{O}\right)$ e fósforo $\left(\mathrm{P}_{2} \mathrm{O}_{5}\right)$, com a adição correspondendo a 13,9mg $\mathrm{dm}^{-3}$ e $41,7 \mathrm{mg} \mathrm{dm}^{-3}$, respectivamente. Aos 30 dias após a semeadura, foi realizada a aplicação de $\mathrm{K}_{2} \mathrm{O}$ em cobertura com $27,8 \mathrm{mg} \mathrm{dm}^{-3}$.

A cultivar de soja utilizada foi a 'P98R31 RR', com $98 \%$ de germinação e pureza. As sementes de soja foram inoculadas 45 minutos antes da semeadura com inoculante à base de turfa, contendo as bactérias Bradyrhizobium elkani (Estirpe Semia 5019) e Bradyrhizobium japonicum (Estirpe Semia 5079), com concentração mínima de $5 \times 10^{9}$ células viáveis por grama de inoculante, na dosagem de $100 \mathrm{~g}$ de inoculante em $50 \mathrm{~kg}$ de semente de soja. Foram semeadas cinco sementes de soja por vaso, sendo realizado o desbaste cinco dias após a emergência, deixando-se duas plantas por vaso, uniformes e equidistantes.

A unidade experimental foi constituída por vaso, contendo $11 \mathrm{~kg}$ de substrato. Os tratamentos foram arranjados em um esquema fatorial $5 \times 5$, com cinco níveis do fator manganês $(\mathrm{Mn})\left(0,20,40,60\right.$ e $\left.80 \mathrm{mg} \mathrm{dm}^{-3}\right)$ e cinco de glifosato $(0 ; 0,648 ; 1,296 ; 1,944$ e $2,592 \mathrm{~kg}$ i.a. $\mathrm{ha}^{-1}$ ). O Mn foi fornecido pelo sulfato de manganês 
$\left(\mathrm{MnSO}_{4} \cdot \mathrm{H}_{2} \mathrm{O}\right)$. O delineamento experimental foi em blocos casualizados, com quatro repetições.

O Mn foi aplicado antes da semeadura. A aplicação do glifosato se deu no período vegetativo (V3), sendo tal aplicação realizada com pulverizador costal pressurizado por $\mathrm{CO}_{2}$ à pressão constante de $2,5 \mathrm{kgf} \mathrm{cm}^{-2}$, equipado com barra de aplicação com ponta do tipo leque, modelo Teejet XL 110.02 VS, calibrado para volume de calda proporcional a $200 \mathrm{~L} \mathrm{ha}^{-1}$.

As avaliações foram efetuadas no estágio V8 (20 dias após a aplicação), separando-se a planta em parte radicular (raízes) e parte aérea (caule e folhas). O material colhido foi lavado com água destilada, secado em estufa com circulação forçada de ar a $65^{\circ} \mathrm{C}$, até atingir massa constante, sendo em seguida pesado a fim de que não ocorresse ganho de umidade e triturado em moinho tipo Willey. A seguir, as amostras do material vegetal seco foi digerido em solução nítricoperclórico $\left(\mathrm{HNO}_{3}: \mathrm{HClO}_{4}\right)$ na proporção 3:1. O teor de $\mathrm{Mn}, \mathrm{Cu}, \mathrm{Zn}$ e $\mathrm{Fe}$ nas amostras foi determinado em espectrofotômetro de absorção atômica modelo PGI 990.

A partir da massa seca e do conteúdo dos nutrientes na planta, foram calculados os índices: (a) eficiência de uso de nutriente $\left(\mathrm{g}^{2} \mathrm{mg}\right)(\mathrm{EFU})=$ (massa seca total produzida) $)^{2}$ (conteúdo total do nutriente na planta) (SIDDIQI \& GLASS, 1981); (b) eficiência de absorção $\left(\mathrm{mg} \mathrm{g}^{-1}\right)(\mathrm{EFA})=($ conteúdo total do nutriente na planta)/(massa seca de raízes) (SWIADER et al., 1994); (c) eficiência de translocação (\%) (EFT) = [(conteúdo do nutriente na parte aérea)/(conteúdo total do nutriente na planta)].100 (LI et al., 1991).

Os dados foram submetidos à análise de variância pelo teste F. Para o caso de diferenças significativas, foi realizada a análise de regressão, até o nível de 5\% de probabilidade, utilizando-se o aplicativo computacional SAEG 9.1.

\section{RESULTADOS E DISCUSSÃO}

As dosagens de glifosato, acima de $0,648 \mathrm{~kg}$ i.a ha ${ }^{-1}$, apresentaram sintomas de injúria nas plantas de soja, sendo a severidade do dano maior à medida que as dosagens do herbicida eram elevadas, apresentando, na dosagem de $0,648 \mathrm{~kg}^{\mathrm{i} . \mathrm{a} \mathrm{ha}}{ }^{-1}$, o menor dano nas plantas, com pouco amarelecimento e necrose nas folhas, seguindo a severidade da injúria com o aumento das dosagens. A mesma cultivar foi semeada ao campo, como lavoura comercial com 350.000 sementes ha ${ }^{-1}$ da cv. 'P98R31 RR'. Aplicando-se 1,944kg i.a. ha ${ }^{-1}$ de glifosato, as plantas apresentaram, após a aplicação (24 horas), sintomas de injúria. Os sintomas visíveis de injúria foram observados, nas plantas, no dia seguinte à aplicação, na casa de vegetação, com amarelecimento das folhas novas seguido de necrose. O herbicida foi aplicado no estádio vegetativo V3. Decorridos 20 dias da aplicação, houve, aparentemente, recuperação das plantas. A injúria ocorrida nas folhas foi local ao tecido que recebeu o herbicida, sendo que, nas folhas desenvolvidas posteriormente, não houve sintoma de injúria.

Resultados semelhantes foram relatados por BELLALOUI et al. (2006), que, após aplicação com glifosato na dosagem comercial em soja RR, observaram sintomas de injúria nas plantas. As injúrias iniciaram com cloroses seguida de necrose, em todos os estágios de crescimento da planta, em folhas novas, seguido da aplicação do glifosato. REDDY \& ZABLOTOWICZ (2003) observaram que, após aplicação do glifosato, ocorreu injúria no tecido foliar. Segundo esses autores, essa injúria é provocada pela proporção de sal que está presente nas formulações comerciais de glifosato e não pelo produto glifosato. REDDY et al. (2004) notaram que, após a aplicação de glifosato em soja RR, a maior concentração de ácido aminometilfosfônico (AMPA), nas folhas, ocorreu um dia após o tratamento (DAT) (42 $\mathrm{mg} \mathrm{g}^{-1}$ de massa seca), sendo que, após esse período, ocorreu redução gradual em sua concentração no tecido, de $42 \mathrm{mg} \mathrm{g}^{-1}$ de MS para $1 \mathrm{mg} \mathrm{g}^{-1}$ de MS, aos 22DAT. Os sintomas de injúria gerados nas plantas dependem das doses de glifosato utilizadas, sendo que as maiores concentrações de glifosato levam a maiores formações do composto secundário AMPA, que pode causar injúria às plantas (ZABLOTOWCZ \& REDDY, 2007). Após duas semanas da aplicação do glifosato, os sintomas de amarelecimento desapareceram, em folhas de soja RR (ZOBIELA et al., 2010b).

Os níveis de manganês (Mn) aplicados no experimento não proporcionaram efeito significativo $(\mathrm{P}>0,05)$ na eficiência nutricional de $\mathrm{N}, \mathrm{Mn}, \mathrm{Zn}, \mathrm{Cu}$ e $\mathrm{Fe}$, no número de nódulos, na massa seca [raiz (MSR), na parte aérea (MSA) e total (MST)] e no teor total de nutrientes na planta.

Não houve efeito significativo $(\mathrm{P}>0,05)$ das dosagens de glifosato na EFA de $\mathrm{Mn}, \mathrm{Cu}$ e $\mathrm{Zn}$ (Figura $1 \mathrm{~A}, 1 \mathrm{~B}$ e 1C). Com o estudo de diferentes formulações comerciais de glifosato aplicadas 25 dias após a semeadura (estádio V2-V3), com $2 \mathrm{~kg}$ i.a. ha ${ }^{-1}$, SANTOS et al. (2007) não observaram alterações nos teores de $\mathrm{Zn}$ e Mn, no tecido foliar da cv. 'CD 219 RG', no período de florescimento.

AEFA de $\mathrm{Ne}$ Fe aumentou com as dosagens de glifosato, observando-se que houve uma resposta linear na EFA de $\mathrm{N}$, com eficiência máxima de absorção para o $\mathrm{N}$ de $120,4 \mathrm{mg} \mathrm{g}^{-1}$, quando aplicou-se 2,592kg i.a. ha $^{-1}$ de glifosato (Figura 1A). Dessa forma, observa-se 


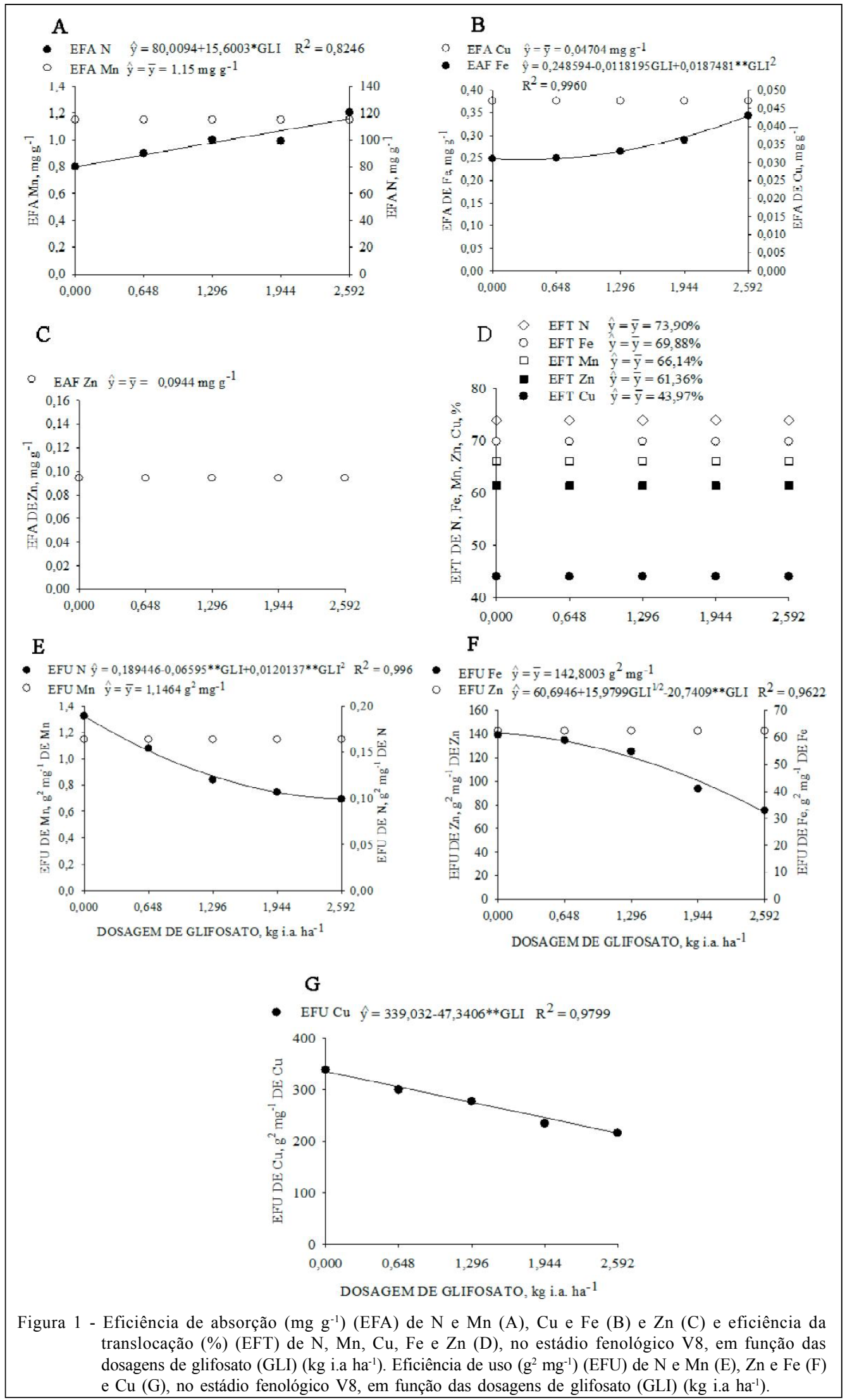

Ciência Rural, v.41, n.1, jan, 2011. 
que, para a produção de $1 \mathrm{~g}$ de massa seca (MS), foram necessários $120,4 \mathrm{mg}$ de $\mathrm{N}$, sendo na ausência de glifosato, com $80 \mathrm{mg}$ de $\mathrm{N}$ produziu $1 \mathrm{~g}$ de MSR. A cv 'P98R31 RR' obteve melhor rendimento na absorção de $\mathrm{N}$ e Fe quando não utilizou glifosato (Figura 1A e 1B). Isso se deve à menor produção de MSR pelas plantas, com a aplicação de glifosato. Assim, o menor rendimento da absorção de Fe pode estar relacionado com a menor eficiência da redutase férrica, pois BELLALOUI et al. (2009) obtiveram resultado negativo na eficiência da redutase férrica com as aplicações de glifosato em soja RR, tendo como resultado menor concentração de Fe foliar e nas sementes.

Observou-se que a EFT de $\mathrm{Cu}, \mathrm{Zn}, \mathrm{Mn}, \mathrm{Fe}$ e $\mathrm{N}$ não diferiram significativamente $(\mathrm{P}>0,05)$ com as dosagens de glifosato em estudo. Dessa forma, não se ajustaram equações de regressão para essas variáveis, sendo o valor estimado das variáveis dependentes igual à média aritmética obtida no ensaio (Figura 1D).

A EFU de $\mathrm{Mn}$ e $\mathrm{Zn}$ não se diferenciou significativamente $(\mathrm{P}>0,05)$ com a aplicação de glifosato
(Figura 1E e 1F). Assim, pode-se inferir que a concentração de Mn e Zn na planta estava sob níveis adequados, mesmo havendo redução dos teores de Mn e Zn na planta, quando se aplicou o glifosato (Figura 2A e 2B). No entanto, essa redução não se deve à influência direta do glifosato sobre o micronutriente, e sim do glifosato sobre a produção de MS.

Já para a EFU de N, Fe e $\mathrm{Cu}$, houve efeito significativo $(\mathrm{P}<0,01)$, evidenciando que, à medida que aumentaram as dosagens de glifosato, reduziu-se a EFU desses nutrientes (Figura 1E, 1F e 1G). Esse efeito se deve à redução do conteúdo total de $\mathrm{N}, \mathrm{Fe}$ e $\mathrm{Cu}$ na planta e à redução da massa seca quando aplicado o glifosato (Figura 2A, 2B, 2C e 2D). Com isso, a relação entre produção de massa seca e teor de nutriente reduziu-se, devido ao efeito das dosagens de glifosato aplicadas.

Com a aplicação de glifosato nas dosagens estudadas, houve diferenças significativas $(\mathrm{P}<0,05)$ para o teor de $\mathrm{Mn}, \mathrm{Fe}, \mathrm{Zn}, \mathrm{Cu}$ e $\mathrm{N}$ total na planta e no

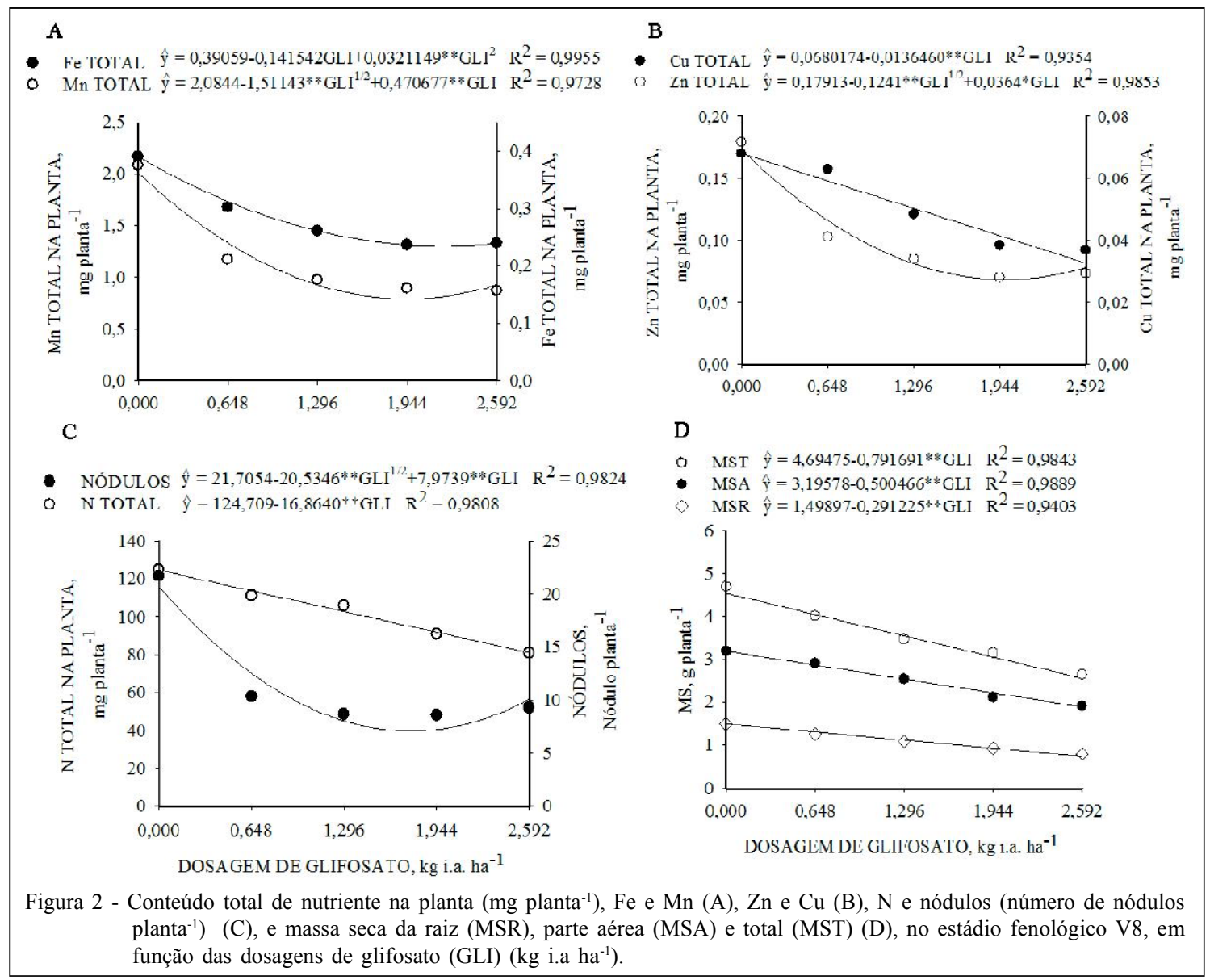

Ciência Rural, v.41, n.1, jan, 2011. 
número de nódulos (Figura 2A, 2B e 2C). Observou-se que as dosagens de glifosato reduziram o conteúdo total desses nutrientes. Essa redução possivelmente se deve à depressão no crescimento da planta causada pela aplicação do glifosato. As dosagens de glifosato acarretaram redução na produção da MSR, MSA e MST (Figura 2D), podendo tal fato ser explicado pela possível redução da fotossíntese, quando da aplicação do herbicida.

Ao estudar a concentração de micronutrientes nas folhas jovens em soja RR cv. 'Valiosa', BOTT et al. (2008) não encontraram diferenças significativas nas dosagens de glifosato utilizadas $\left(0,9 \mathrm{~kg}\right.$ i.a ha ${ }^{-1}$ e $1,8 \mathrm{~kg}$ i.a ha $\left.{ }^{-1}\right)$. Segundo REDDY et al. (2004), a toxidez de AMPAé responsável pela depressão do crescimento. Os mesmos autores concluíram que a injúria causada quando da aplicação do glifosato em soja RR se deve à produção do AMPA, que se forma como produto da degradação do glifosato. A dosagem de AMPA de $0,12 \mathrm{~kg} \mathrm{ha}^{-1}$ reduziu o conteúdo de clorofila nas folhas de soja RR, havendo também diferenças na sensibilidade ao AMPA na soja RR e não RR, sendo essas devidas às diferentes cultivares utilizadas. $O$ nível de AMPA de 4-7 $\mu \mathrm{g} \mathrm{g}^{-1}$ de massa seca causou redução no conteúdo de clorofila, tanto em plantas RR, quanto em plantas não RR, mediante a aplicação de AMPA nessas plantas o chiquimato não foi afetado, o que indica que não age como o glifosato na inibição da EPSPS, sendo o AMPA um composto fitotóxico às plantas, que causa a redução do conteúdo de clorofila e produção de massa seca aérea da planta, com um mecanismo de ação desconhecido (REDDY et al., 2004).

Nos resultados obtidos, pode-se observar que o número máximo de nódulos (22 nódulos planta $\left.{ }^{-1}\right)$ foi obtido na ausência de glifosato. Com a aplicação de glifosato, o número de nódulos reduziu-se em $50 \%$, em média, na dose máxima de glifosato, sendo essa variação significativa $(\mathrm{P}<0,01)$, quando comparada com o controle (Figura 2C). REDDY et al. (2000) constataram que a aplicação de $2,24 \mathrm{~kg}$ i.a ha ${ }^{-1} \mathrm{em}$ estádio vegetativo de soja RR promoveu redução de $30 \%$ no número de nódulos, de $39 \%$ na massa de nódulos e de $14 \%$ no conteúdo total de $\mathrm{N}$ na parte aérea. Com a aplicação de 3,36kg i.a. ha ${ }^{-1}$ de glifosato, BELLALOUI et al. (2008) observaram redução na atividade da redutase do nitrato (RN), nos nódulos, nas raízes, nos caules e nos trifólios da planta de soja RR, sendo essa avaliação realizada uma semana após a aplicação do glifosato. REDDY et al. (2010) obtiveram como resultado que a redução da atividade da RN está relacionada com a concentração da dose de glifosato aplicada, sendo que, ao se aplicar duas vezes a dose $840 \mathrm{~g}$ i.a ha ${ }^{-1}$, reduziu-se entre $5-19 \%$ a atividade da enzima, e, com duas aplicações de 1.360i.a $\mathrm{ha}^{-1}$, a atividade da mesma variou entre $8-42 \%$.
Devido à sensibilidade da (EPSPS) presente no Bradyrhizobium sp, possivelmente um dos fatores que possibilitou a redução do conteúdo total de $\mathrm{N}$ na planta, com aumento das dosagens de glifosato no presente trabalho, deva-se a ação inibitória do glifosato, na EPSPS. Esse resultado pode ainda estar associado à redução do número de nódulos nas plantas tratadas e a injúria provocada na planta quando se aplica o herbicida, que pode reduzir a eficiência fotossintética. DE MARIA et al. (2005) observaram que o glifosato causa alteração no metabolismo nodular devido à limitação do fornecimento de carboidrato das folhas e caules para os nódulos. O glifosato pode levar à redução do $\mathrm{Ni}$, que é um elemento essencial aos microrganismos fixadores de $\mathrm{Ne}$ e, dessa forma, reduzir a fixação simbiótica desse elemento (ZOBIELA et al., 2010a). Ao avaliar a influência do glifosato nos microrganismos no solo, GOMEZ et al. (2009) constataram que doses acima das recomentadas $(>1,92 \mathrm{~L}$ i.a ha ${ }^{-1}$ ) causam redução na biomassa microbiana, sendo tal efeito temporário.

A redução na MS da planta (Figura 2D) possivelmente deve ter ocorrido devido ao estresse fisiológico que as plantas passaram quando da aplicação de glifosato, pois as mesmas apresentaram sintomas de injúrias, logo após a aplicação do glifosato. Os sintomas se intensificavam à medida que aumentavam as doses de glifosato. Mesmo as plantas tendo se recuperado após 20 dias, o estresse pelo qual passaram pode ter resultado na menor produção de massa seca e na redução do conteúdo total de $\mathrm{Fe}, \mathrm{Mn}$, $\mathrm{Cu}, \mathrm{Zn}, \mathrm{N}$ e do número de nódulos (Figura 2A, 2B, $2 \mathrm{C} \mathrm{e}$ 2D). BELLALOUI et al. (2008) relataram que a presença de sintomas de injúria foi reduzindo com o passar do tempo, com as plantas recuperando-se completamente após 14 dias da aplicação com glifosato. ZABLOTOWICZ \& REDDY (2007) expuseram que a produção de biomassa de raízes de soja com aplicações de glifosato $2,52 \mathrm{~kg}$ i.a. ha ${ }^{-1}$ foi $20-25 \%$ inferior que o controle, sem aplicação de glifosato, em 7 e 8 semanas após semeadura, respectivamente. Em estudos anteriores, com a aplicação de glifosato de $1,68 \mathrm{~kg}$ i.a. ha $^{-1}$ (REDDY et al., 2000) e 6,3kg i.a. ha ${ }^{-1}$ (KING et al., 2001), constatou-se a redução de MSA e MSR, em experimentos realizados em condições controladas de casa de vegetação.

\section{CONCLUSÃO}

Não houve influência na resposta das plantas com relação aos níveis de Mn utilizados no experimento. Aaplicação de glifosato interferiu de forma negativa na eficiência de: absorção de $\mathrm{N}$ e Fe, uso de 
$\mathrm{N}, \mathrm{Fe}$ e $\mathrm{Cu}$ na planta e nos teores totais de N, Mn, Zn, $\mathrm{Cu}$ e Fe. Não houve efeito na eficiência de translocação dos nutrientes avaliados na planta, mediante os tratamentos utilizados. A utilização de glifosato nas condições de casa de vegetação causou redução no número de nódulos na soja cv. 'P98R31 RR'. A produção de massa seca reduziu-se com o aumento das dosagens de glifosato.

\section{REFERÊNCIAS}

BELLALOUI, N. et al. Effects of glyphosate application on seed iron and root ferric (III) reductase in soybean cultivars. Journal of Agricultural and Food Chemistry, v.57, p.95699574, 2009. Disponível em: <http://pubs.acs.org $>$. Acesso em: 21 jul. 2009. doi: 10.1021/jf902175y.

BELLALOUI, N. et al. Nitrogen metabolism and seed composition as in?uenced by glyphosate application in glyphosate-rsistant soybean. Journal of Agricultural and Food Chemistry, v.56, n.8, p.2765-2772, 2008. Disponível em: <http://pubs.acs.org>. Acesso em: 21 jul. 2009. doi: $10.1021 / \mathrm{jf} 703615 \mathrm{~m}$.

BOTT, S. et al. Glyphosate-induced impairment of plant growth and micronutrient status in glyphosate-resistant soybean (Glycine $\max$ L.). Plant and Soil, v.312, p.185-194, 2008. Disponível em: <http://www.springerlink.com/content/c41002503810711p/>. Acesso em: 10 nov. de 2009. doi: 10.1007/s11104-008-9760-8.

CAKMAK, I. et al. Glyphosate reduced seed and leaf concentrations of calcium, manganese, magnesium, and iron in non-glyphosate resistant soybean. Europe Journal of Agronomy, v.31, p.114119, 2009. Disponível em: <http://www.sciencedirect.com/ science ob=ArticleListURL\& method $=1$ ist \& ArticleListID $=14$ $57049293 \&$ \&sort $=\mathrm{r} \&$ _st $=13 \& \mathrm{view}=\mathrm{c} \&$ acct $=\mathrm{C} 000050221 \&$ \&ve rsion $=1 \&$ urlVersion $=0 \& \_u s e r i d=10 \& \mathrm{md} 5=\mathrm{e} 661 \mathrm{ea} 672986 \mathrm{~d} 501 \mathrm{c} 8$ 795aef408c11d6\&searchtype $=\mathrm{a}>$. Acesso em: 21 jul. 2009. doi: 10.1016/j.eja.2009.07.001.

DE MARÍA, N. et al. Alterations induced by glyphosate on lupin photosynthetic apparatus and nodule ultrastructure and some oxygen diffusion related proteins. Plant Physiology Biochemistry, v.43, p.985-996, 2005. Disponível em: <http:/ /www.springerlink.com/index/c41002503810711p>. Acesso em: 10 nov. 2009. doi:10.1016/j.plaphy.2005.09.001.

EKER, S. et al. Foliar applied glyphosate substantially reduced uptake and transport of iron and manganese in sunflower (Helianthus annuus L.). Journal of Agricultural and Food Chemistry, v.54, n.26, p.10019-10025, 2006. Disponível em: <http://pubs.acs.org>. Acesso em: 21 jul. 2009. doi: $10.1021 /$ jf0625196.

EMPRESA BRASILEIRA DE PESQUISA AGROPECUÁRIA EMBRAPA. Centro nacional de pesquisa de solos (Rio de Janeiro, RJ). Manual de métodos de análise de solo. 2.ed. Rio de Janeiro: 1997. 212p.

EMPRESA BRASILEIRA DE PESQUISA AGROPECUÁRIA EMBRAPA. Centro nacional de pesquisa de solos (Rio de Janeiro, RJ). Sistema brasileiro de classificação de solos. Brasília: 2006. 169 p.
GOMEZ, E. et al. Impact of glyphosate application on microbial biomass and metabolic activity in a Vertic Argiudoll from Argentina. European Journal of Soil Biology, v.45, p.163167, 2009. Disponível em: <http://www.springerlink.com/ content/c41002503810711p/>. Acesso em: 10 jul. 2010. doi:10.1016/j.ejsobi.2008.10.001.

KING, C.A. et al. Plant growth and nitrogenase activity of glifosato-tolerant soybean in response to foliar glifosato applications. Agronomy Journal. v.93, p.176-186, 2001.

LI, B. et al. Genetic variation in nitrogen use efficiency of loblolly pine seedlings. Forest Science, v.37, p.613-626, 1991.

NEUMANN, G. et al. Relevance of glyphosate transfer to non-target plants via the rhizosphere. Journal for Plant Disease and Protection, v.20, p.963-969, 2006.

PADGETTE, S.R. et al. New weed control opportunities: development of glifosato-tolerant soybeans. In: DUKE, S.O. (Ed.). Herbicide resistant crops. Boca Raton, CRC, 1995. p.54-80.

REDDY, K.N. et al. Glyphosate effect on shikimate, nitrate reductase activity, yield, and seed composition in corn. Journal of Agricultural and Food Chemistry, v.58, p.3646-3650, 2010. Disponível em: <http://pubs.acs.org/action/ doSearch?action=search\&searchText=BELLALOUI\&qsSearchAre $\mathrm{a}=$ searchText\&type $=$ within\&publication $=40026026>$. Acesso em: 10 jul. 2010 . doi: $10.1021 /$ jf904121y.

REDDY, K.N. et al. Aminomethylphosphonic acid, a metabolite of glyphosate, causes injury in glyphosate-treated, glyphosate-resistant soybean. Journal of Agricultural and Food Chemistry, v.52, p.5139-5143, 2004. Disponível em: <http://pubs.acs.org/action/ doSearch?action=search\&searchText=Krishna $+N$. + Reddy\&qsSearchAr ea $=$ searchText $>$. Acesso em: 22 nov. 2009. doi: 10.1021/jf049605v.

REDDY, K.N.; ZABLOTOWICZ, R.M. Glyphosate-resistant soybean response to various salts of glyphosate and glyphosate accumulation in soybean nodules. Weed Science, v.51, n.4, p.496-502, 2003. Disponível em: <http://wssajournals.org/doi/full/10.1614/00431745\%282003\%29051\%5B0496\%3AGSRTVS\%5D2.0.CO\%3B2>. Acesso em: 10 de nov. 2009. doi: 10.1614/0043-1745.

REDDY, K.N. et al. Effect of glyphosate on growth, chlorophyll, and nodulation in glyphosate-resistant and susceptible soybean (Glycine max) varieties. Journal of New Seeds, v.2, n.3, p.3752, 2000. Disponível em: <http://www.informaworld.com/smpp/ content $\sim \mathrm{db}=$ all $\sim$ content $=\mathrm{a} 903885519 \sim \mathrm{frm}=$ titlelink ? words $=$ reddy \& hash $=3297636493>$. Acesso em: 10 nov. 2009. doi: 10.1300/ J153v02n03 03 .

SANTOS, J.B. et al. Avaliação de formulações de glifosato sobre soja Roundup Ready. Planta Daninha, v.25, n.1, p.165-171, 2007. Disponível em: $<\mathrm{http}: / / w w w . s c i e l o . b r / s c i e l o . p h p ?$ pid $=\mathrm{S} 0100-$ $83582007000100018 \&$ script $=$ sci_arttext\&tlng $=$ in $>$. Acesso em: 10 nov. 2009. doi: 10.1590/S0100-83582007000100018.

SIDDIQI, M.; GLASS, A.D.M. Utilization index: a modified approach to the estimation and comparison of nutrient utilization efficiency in plants. Journal of Plant Nutrition, v.4, p.289-302, 1981.

SWIADER, J.M. et al. Genotypic differences in nitrate uptake and utilization efficiency in pumpkin hybrids. Journal of Plant Nutrition, v.17, p.1687-1699, 1994. 
ZABLOTOWICZ, R.M.; REDDY, K.N. Nitrogenase activity, nitrogen content, and yield responses to glyphosate in glyphosate-resistant soybean. Crop Protection, v.26, p.370376, 2007. Disponível em: <http://www.sciencedirect.com/ science? ob $=$ PublicationURL\&_tockey $=\% 23 \mathrm{TOC} \% 235011 \% 23$ $2007 \% 23999739996 \% 23642377 \% 23$ FLA $\% 23 \&$ cdi $=5011 \&$ 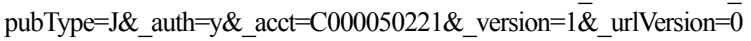 $\&$ userid $=10 \&$ md $5=2 \mathrm{a} 9 \mathrm{a} 3 \mathrm{~b} 33 \mathrm{f} 063 \mathrm{a} 6 \mathrm{f} 38 \mathrm{e} 0126 \mathrm{~d} 93574922 \mathrm{a}>$. Acesso em: 10 nov. 2009. doi:10.1016/j.cropro.2005.05.013 .

ZOBIOLE, L.H.S. et al. Effect of glyphosate on symbiotic N2 fixation and nickel concentration in glyphosateresistant soybeans. Applied Soil Ecology, v.44, p.176180, 2010a. Disponível em: <http://www.sciencedirect.com/
science?_ob=PublicationURL\&_tockey $=\% 23$ TOC $\% 234970 \% 2320$ 10\%23999559997\%231578639\%23FLA \%23\&_cdi=4970\&_ pubType $=J \& \_a u t h=y \& \_a c c t=C 000050221 \& \_$version $=1 \&$ urlVersio $\mathrm{n}=0 \&$ userid $=10 \& \mathrm{md} 5=\mathrm{f} 9 \mathrm{c} 20 \mathrm{a} 05 \mathrm{f} 5645 \mathrm{cf} 4565 \mathrm{a} 53 \mathrm{f} 18 \mathrm{df} 6 \mathrm{~d} 45 \mathrm{f}>$. Acesso em: 01 jul. 2010. doi:10.1016/j.apsoil.2009.12.003.

ZOBIOLE, L.H.S. et al. Glyphosate affects seed composition in glyphosate-resistant soybean. Journal of Agricultural and Food Chemistry, v.58, p.4517-4522, 2010b. Disponível em: <http://pubs.acs.org/action/ doSearch?action=search\&searchText=BELLALOUI\&qsSearchArea $=$ searchText\&type $=$ within \&publication $=40026026>$. Acesso em: 10 jul. 2010 . doi: $10.1021 / \mathrm{jf} 904342 \mathrm{t}$. 